on the $\beta$-helix transition of poly-L-lysine in sodium dodecyl sulfate solution. Biopolymers 14: 1841-1846, 1975.

17. Sarker $\mathbf{P K}$ and Doty $\mathbf{P}$, 'I he optical rotatory properties of the $\beta$-configuration in polypeptides and proteins. Proc Natl Acad Sci USA 55: 981-989, 1966.
18. Watanabe $\mathrm{S}$ and Saito $\mathrm{T}, \mathrm{ACD}$ study of the role of metal ions in the conformation of poly(L-Lysine). Biopolymers 26: 625-632, 1987.

19. Davidson B and Fasman GD, The conformational transitions of uncharged poly-L-lysine. $\alpha$ Helix-random coil- $\beta$ structure. Biochemistry 6: 1616-1629, 1967.

\title{
Biochemical and biological properties of methotrexate analogs containing D-glutamic acid or D-erythro,threo-4-fluoroglutamic acid
}

(Received 6 May 1991; accepted 30 July 1991)

Structural modification of existing antifolates may create new agents with altered therapeutic effects [1]. For example, substitution of an amino acid analog for $L^{-}$ glutamate (Glu) in classical antifolates may alter enzyme inhibition, transport properties, or the ability to form poly$\gamma$-glutamate metabolites [1]. Often, the amino acid analog chosen is only or most readily available as the D,L-racemate. Thus, the D,L-racemate may be used to synthesize the analog first; if interesting biological results are obtained, the analog containing the L-enantiomer may be prepared. It is generally assumed in studies using a D.L-racemate that the $\mathrm{D}$-enantiomer-containing analog is inactive and does not interfere with effects of the L-enantiomer-containing species. In the case of methotrexate $\left(\mathrm{MTX}^{*}\right)$, this assumption has been validated only for D-MTX compared to L-MTX [2].

We previously studied D,L-e,t- $\gamma$-fluoroMTX (4-amino10-methylpteroyl-D, L-erythro,threo-4-fluoroGlu; $\mathrm{D}, \mathrm{L}-e, t-$ FMTX), an MTX analog in which L-Glu is replaced by D,L-erythro,threo-4-fluoroGlu, and its constituent diastereomers $\mathrm{D}, \mathrm{L}-e$-FMTX and D,L-t-FMTX [3-5]. Based on published studies of D-MTX [2], we assumed that the $D$-enantiomer-containing species were essentially inactive. However, we remained concerned about the remote possibility that fluorine substitution might alter enantiomeric specificity in our test systems. To address this concern, we enzymatically prepared D-e, $t$-FMTX and studied its activity. We included D-MTX in these studies to expand the data base on this contaminant found in clinical MTX preparations [2].

\section{Materials and Methods}

L-MTX was a gift of Lederle (Pearl River, NY). D, Land D-MTX were from Aldrich Chemicals (Milwaukee, WI). 4-Amino-10-methylpteroyl[ $\gamma$-( $1 H$-tetrazolyl- 5-yl)-L$\alpha$-amino butyric acid] [6] was a gift of Dr. T. Kalman (SUNY, Buffalo, NY). 4-Amino-10-methylpteroyl-D,L-(3hydroxy-Glu) and 4-amino-10-methylpteroyl-D,L-(4methylene-Glu) [7] were gifts of Dr. M. G. Nair (University of South Alabama, Mobile). Other chemicals were reagent grade or higher.

D-e,t-FMTX was prepared by exhaustive digestion of $D, L-e, t$-FMTX [3] with carboxypeptidase $\mathrm{G}_{2}\left(\mathrm{CPG}_{2}\right)$, which

* Abbreviations: MTX, methotrexate; D,L-e,t- $\gamma$-fluoroMTX (D,L-e,t-FMTX), 4-amino-10-methylpteroyl-D,Lerythro,threo-4-fluoroGlu; $\mathrm{CPG}_{2}$, carboxypeptidase $\mathrm{G}_{2}$; DHFR, dihydrofolate reductase; and dTMP. thymidylate. specifically releases L-amino acids from pteroates (vide infra $)$. D, L-e,t-FMTX $(20 \mu \mathrm{mol})$ was hydrolyzed $\left(37^{\circ}\right)$ by 40 I.U. of $\mathrm{CPG}_{2}$ in $25 \mathrm{mM}$ Tris-Cl, pH 7.3 and $0.1 \mathrm{mM}$ $\mathrm{ZnCl}_{2}(200 \mathrm{~mL})$. After no further absorbance change at $320 \mathrm{~nm}$ was observed $(\mathrm{t}=15 \mathrm{~min})$, incubation was continued for $30 \mathrm{~min}$. Based on $\Delta A_{320}$ and the $\mathrm{E}_{320 . \mathrm{pH}} 73$ for production of 4-amino-10-methylpteroate [8], 49\% of the substrate was hydrolyzed. The resulting solution was chromatographed in two portions on DE- $52(0.7 \times 21 \mathrm{~cm}$; Whatman, Clifton, $\mathrm{NJ}$ ) equilibrated at $4^{\circ}$ with $50 \mathrm{mM} \mathrm{NH} \mathrm{HCO}_{3}, \mathrm{pH} 8.0$. After loading and washing with $70 \mathrm{~mL}$ of initial buffer. each column was eluted with a linear gradient $(500 \mathrm{~mL}$ total) from 50 to $200 \mathrm{mM} \mathrm{NH}_{4} \mathrm{HCO}_{3}, \mathrm{pH} \mathrm{8.0.} \mathrm{4-Amino-}$ 10-methylpteroate, identified by its UV spectrum at $\mathrm{pH} 13$ and HPLC retention time [9], was well resolved from D$e, t$-FMTX. Fractions containing material with a UV spectrum and HPLC retention time similar to $\mathrm{D}, \mathrm{L}-e, t-$ FMTX were lyophilized. Exhaustive $\mathrm{CPG}_{2}$ digestion of this material showed it contained $<4 \%$ of the L-isomer (D-e,tFMTX does not inhibit $\mathrm{CPG}_{2}$; vide infra).

Radiochemicals. L- $\left[3^{\prime}, 5^{\prime}, 7^{\prime},-{ }^{3} \mathrm{H}\right] \mathrm{MTX}(20 \mathrm{Ci} / \mathrm{mmol})$ and $\left[5-{ }^{3} \mathrm{H}\right] \mathrm{dUrd}(22 \mathrm{Ci} / \mathrm{mmol})$ were from Moravek Biochemicals (Brea, CA). The purity of $\mathrm{L}-\left[{ }^{3} \mathrm{H}\right] \mathrm{MTX}$ was assessed by HPLC [4].

Enzymes and assays. $\mathrm{CPG}_{2}$ was purified [10] from Escherichia coli harboring a plasmid containing the Pseudomonas $\mathrm{CPG}_{2} \mathrm{CDNA}_{\text {[11] }}$ and assayed as described [8], except that $100 \mu \mathrm{M}$ L-MTX was used. Dihydrofolate reductase (DHFR; EC 1.5.1.3) was partially purified from CCRF-CEM cells and assayed as described [6]. Drug concentrations inhibiting DHFR activity $\left(1.6 \times 10^{-3} \mathrm{I}\right.$ I.U.) by $50 \%\left(\mathrm{IC}_{50}\right)$ were determined as described [6]. L- $\left[{ }^{3} \mathrm{H}\right]-$ MTX uptake by CCRF-CEM cells was measured as described [4].

Cell culture. Human T-lymphoblastic CCRF-CEM [12] and sublines MTX resistant via decreased transport [13] or DHFR increase [14] were cultured in RPMI 1640 containing $10 \%$ horse serum (GIBCO) and additions as indicated [4]. Cell outgrowth inhibition and drug concentration inhibiting cell growth by $50 \%\left(\mathrm{EC}_{50}\right)$ were determined as described [6]. CCRF-CEM cells used as a DHFR source and to determine $\mathrm{EC}_{50}$ were Mycoplasma free (Gen-Probe Inc., San Diego, CA). Studies on thymidylate (dTMP) biosynthesis and inhibition of $\left[{ }^{3} \mathrm{H}\right] \mathrm{MTX}$ uptake were completed within 11 days and 2 months, respectively, of this negative test; testing 10 months later showed contamination in all lines. D-e,t-FMTX was depleted prior to this discovery so the studies could not be repeated. However, since cells grew normally during the studies 
Table 1. Inhibition of CCRF-CEM DHFR and cell outgrowth by MTX analogs containing enantiomers and analogs of L-Glu.

\begin{tabular}{lccc}
\hline & \multicolumn{2}{c}{ DHFR inhibition } & Growth inhibition \\
\cline { 2 - 3 } Compound & $\mathrm{IC}_{50}(\mathrm{nM})$ & Slope $^{*}$ & \\
\hline L-MTX & $0.62 \pm 0.06$ & $1.49 \pm 0.16$ & 16 \\
D,L-MTX & 1.15 & 1.35 & 29 \\
D-MTX & 5.6 & 0.84 & 535 \\
D,L-e,t-FMTX & 1.25 & 1.25 & 73 \\
D-e,t-FMTX & 5.2 & 0.96 & 690 \\
\hline
\end{tabular}

Inhibition of DHFR was determined as described in Materials and Methods. Values are averages of duplicate determinations, except for L-MTX which is the mean $\pm S D(N=3)$. Inhibition of outgrowth of CCRF-CEM cells was measured over $120 \mathrm{hr}$; drug was present throughout the growth period. Results of the outgrowth studies are averages of duplicate values.

* Slope of linear regression of a plot of $\log \left[v /\left(V_{\text {control }}-v\right)\right]$ vs $\log$ [Inhibitor] for each concentration-inhibition curve; the slope quantitates the sigmoidicity of the curve [17].

presented and control values in each case were similar to those we previously reported with pure cultures $[5,6]$, we believe the cells in the reported studies were not contaminated.

Biosynthesis of dTMP. De novo synthesis of dTMP was measured by incubating cells with $\left[5-{ }^{3} \mathrm{H}\right] \mathrm{dUrd}$ and measuring release of ${ }^{3} \mathrm{H}_{2} \mathrm{O}$ as a function of time [6].

\section{Results and Discussion}

$C P G_{2}$ specificity. $\mathrm{CPG}_{2}$ is believed to be similar to $\mathrm{CPG}_{1}$ which specifically hydrolyzes C-terminal L-Glu, L-Asp, and L-Gln from oligopeptides, $\mathrm{N}$-acylated amino acids, folates, and folate analogs $[2,8]$. Stereospecificity of $C P G_{2}$ was verified by showing that, at $100 \mu \mathrm{M}, \mathrm{D}-\mathrm{MTX}$ was hydrolyzed at $<0.2 \%$ the rate of L-MTX; the low rate measured may result from L-MTX contamination since limit digestion of D-MTX indicated the presence of $\leqslant 2 \%$ L-MTX. Also, over $10-50 \mu \mathrm{M}$ L-MTX, the hydrolysis rate was the same for $\mathrm{L}$ MTX or D,L-MTX and the $E_{320}$ for the reaction with D,LMTX was $\approx 50 \%$ that with L-MTX $\left(3900\right.$ vs $7660 \mathrm{~cm}^{-1}$ $\mathrm{M}^{-1}$ ). Quantitation of $20 \mu \mathrm{M}$ L-MTX based on $\mathrm{CPG}_{2-}$ catalyzed hydrolysis was unaffected by the presence of $100 \mu \mathrm{M}$ D-MTX or $40 \mu \mathrm{M}$ D-e,t-FMTX. Thus, similar to $\mathrm{CPG}_{1}[8], \mathrm{CPG}_{2}$ was specific for L-Glu and $\mathrm{D}-\mathrm{Glu}$ did not inhibit its action [2].

4- Amino- 10 - methylpteroyl $[\gamma-(1 H$-tetrazolyl-5-yl)- L- $\alpha$ aminobutyric acid], 4-amino-10-methylpteroyl-D,L-(3-hydroxy-Glu), and 4-amino-10-methylpteroyl-D,L-(4-methylene-Glu) were hydrolyzed 100,50 , and $0 \%$, respectively, by $\mathrm{CPG}_{2}$. These data (not shown) suggested that some Glu analogs could be released in an apparently L-enantiomerspecific manner, but demonstrated sensitivity of $\mathrm{CPG}_{2}$ towards $\gamma$-substituents. Thus if $\mathrm{D}, \mathrm{L}-e, t$-FMTX were a substrate, only the L-enantiomer might be hydrolyzed.

$\mathrm{D}, \mathrm{L}-\mathrm{e}, \mathrm{t}$-FMTX was resistant to $\mathrm{CPG}_{2}$ digestion compared to D,L-MTX. At $200 \mu \mathrm{M}, \mathrm{D}, \mathrm{L}-e, t-\mathrm{FMTX}$ was 7 - to 9-fold less active than D,L-MTX $\left(K_{m, L-M T X}=8 \mu \mathrm{M}\right)$ as a substrate (not shown) suggesting a lower $V_{\max }$ for $\mathrm{CPG}_{2}$ with 4fluoroGlu-containing species. Limit digestion was effected, however, by increasing the $\mathrm{CPG}_{2}$ level; the $\mathrm{E}_{320}$ for hydrolysis of $\mathrm{D}, \mathrm{L}-e, t$-FMTX was the same as for $\mathrm{D}, \mathrm{L}-\mathrm{MTX}$ and thus $50 \%$ of the starting material was hydrolyzed. This was consistent with L-erythro and L-threo isomers both being hydrolyzed. The slower hydrolysis rate of $\mathrm{D}, \mathrm{L}-e, t-$ FMTX by $\mathrm{CPG}_{2}$ is reminiscent of the decreased sensitivity of other 4-fluoroGlu-containing antifolates to $\gamma$-glutamyl hydrolase activity [15]; scissilc peptide bonds in proximity to fluorine may thus generally be less susceptible to enzymatic hydrolysis.

DHFR inhibition. DHFR is the primary target of MTX

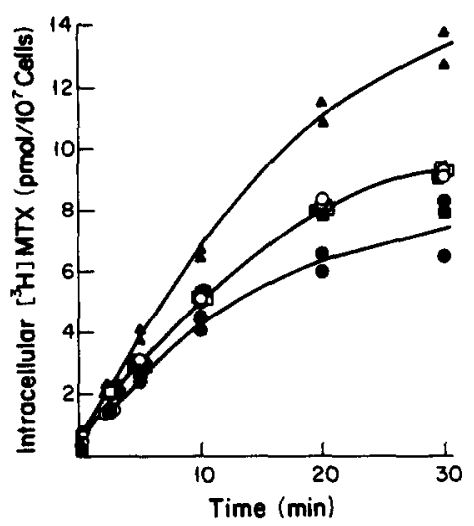

Fig. 1. Inhibition of initial uptake and accumulation of $\left[{ }^{3} \mathrm{H}\right] \mathrm{MTX}$ in CCRF-CEM cells by MTX analogs containing enantiomers and analogs of L-Glu. Cells were added to incubation tubes already containing sufficient $\left[{ }^{3} \mathrm{H}\right] \mathrm{MTX}$ $(0.75 \mu \mathrm{Ci} / \mathrm{mL} ; 760 \mathrm{cpm} / \mathrm{pmol})$ and compound of interest to give final concentrations of $1 \mu \mathrm{M}\left[{ }^{3} \mathrm{H}\right] \mathrm{MTX}$ and: solvent control (A); $4 \mu \mathrm{M}$ D,L-MTX (O); $20 \mu \mathrm{M} \mathrm{D-MTX} \mathrm{(O);8} \mu \mathrm{M}$

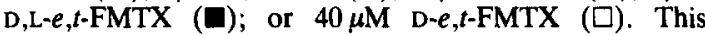
experiment was repeated with similar results.

and its analogs [16]. All MTX analogs tested here inhibited CCRF-CEM DHFR (Table 1). The $\mathrm{IC}_{50}$ for D, L-MTX was about twice that for L-MTX. D-MTX and D-e,t-FMTX had $\mathrm{IC}_{50}$ values 4 -fold higher than the corresponding $\mathrm{D}, \mathrm{L}$ mixtures. In addition to higher $\mathrm{IC}_{50}$ values, slopes of linear transformations of the inhibition curves [17] were lowest for the D-enantiomers (Table 1), further indicating weaker interaction with DHFR. Previous work also showed that D-MTX was weaker than L-MTX as an inhibitor of human and murine DHFR based on $\mathrm{IC}_{50}$ values [2]. Slopes of inhibition curves were not reported in that study.

$\left[{ }^{3} \mathrm{H}\right] M T X$ uptake inhibition. MTX and FMTX isomers share transport systems in H35 hepatoma [3] and CCRFCEM cells [4]. Preliminary studies showed that $4 \mu \mathrm{M}$ D, LMIX was equivalent to $2 \mu \mathrm{M}$ L-MIX in decreasing the initial velocity $\left(v_{i}\right)$ of transport and accumulation at $30 \mathrm{~min}$ of $1 \mu \mathrm{M} L-\left[{ }^{3} \mathrm{H}\right] \mathrm{MTX}$. D-MTX at $\leqslant 10 \mu \mathrm{M}$ had no effect on $v_{i}$ and caused only a slight decrease in accumulation at 30 min (not shown); $20 \mu \mathrm{M}$ D-MTX affected both $v_{i}$ and accumulation at $30 \mathrm{~min}$, but the effect was less than that of $4 \mu \mathrm{M}$ D,L-MTX (Fig. 1). Effects of D-MTX on MTX 


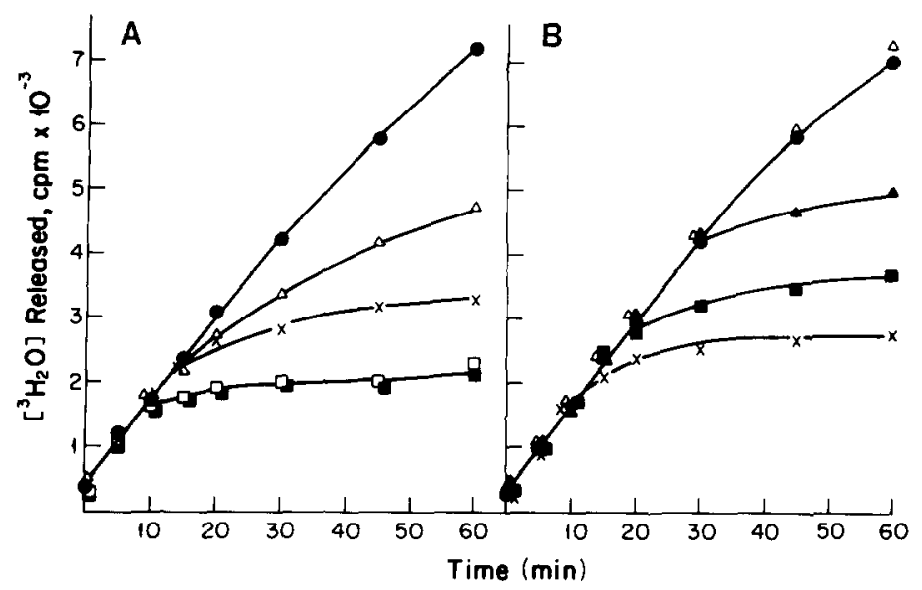

Fig. 2. Inhibition of thymidylate biosynthesis in CCRF-CEM cells by MTX analogs containing enantiomers and analogs of $\mathrm{L}-$ Glu. Cells were added to incubation tubes already containing $\left[5-{ }^{3} \mathrm{H}\right] \mathrm{dUrd}$ $(1 \mu \mathrm{Ci} / \mathrm{mL})$ to give a final concentration of $45 \mathrm{nM}$; the compound of interest was present simultaneously to give the final indicated concentration. $\left[5-{ }^{3} \mathrm{H}\right] \mathrm{dU}$ rd metabolism was measured as described in Materials and Methods. Panel A: Solvent control (O);0.5 $\mu \mathrm{M}$ L-MTX $(\times) ; 1 \mu \mathrm{M}$ L-MTX ( $\square) ; 2 \mu \mathrm{M}$ D,L-MTX

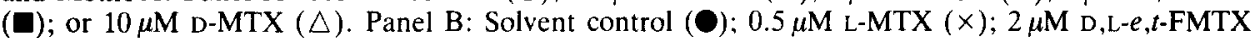
(G); $2.8 \mu \mathrm{M}$ D-e,t-FMTX $(\triangle)$; or $10 \mu \mathrm{M}$ D-e,t-FMTX ( $\Delta$ ). This experiment was repeated with similar results.

transport were not examined previously [2]. D.L-e,t-FMTX at $8 \mu \mathrm{M}$ inhibited $\mathrm{L}-\left[{ }^{3} \mathrm{H}\right] \mathrm{MTX}$ uptake: $40 \mu \mathrm{M}$ D-e.t-FMTX was required to achieve the same level of inhibition (Fig. 1). Thus, D-MTX and D-e,t-FMTX were much weaker than the corresponding $\mathrm{L}$-enantiomers as inhibitors of $\mathrm{L}-\left[{ }^{3} \mathrm{H}\right]$ MTX uptake. Assuming that inhibitory potency reflects affinity for the carrier and that other routes of transport are not used at higher efficiency, these data suggest that D-cnantiomers are poorly transported.

Uptake measurements. An attempt was made to use $\mathrm{CPG}_{2}$ hydrolysis to assess the enantiomeric composition of intracellular radiolabel following exposure of CCRF-CFM cells to L- $\left[{ }^{3} \mathrm{H}\right] \mathrm{MTX}$ or D,L-erythro- $\left[{ }^{3} \mathrm{H}\right]$ FMTX. L- $\left[{ }^{3} \mathrm{H}\right] \mathrm{MTX}$ and $\mathrm{D}, \mathrm{L}$-erythro- $-\left[{ }^{3} \mathrm{H}\right] \mathrm{FMTX}[4]$ were hydrolyzed by $\mathrm{CPG}_{2}$ to yield $\geqslant 96 \%$ and $45 \%$ [ $\left.{ }^{3} \mathrm{H}\right] 4$-amino-10-methylpteroate. respectively, indicating that the approach was feasible. The extensive sample processing required in cell studies, however, resulted in significant conversion of radiolabel to unidentifiable products even in control samples; thus intracellular drug could not be studied.

Inhibition of dTMP biosynthesis. dTMP biosynthesis was measured by conversion of $\left[5-{ }^{3} \mathrm{H}\right] \mathrm{dU}$ Ud to dTMP in intact cells. Inhibition by L-MTX was concentration-dependent and $2 \mu \mathrm{M}$ D,L-MTX was equivalent to $1 \mu \mathrm{M}$ L-MTX (Fig. 2A). D-MTX at $10 \mu \mathrm{M}$ inhibited dTMP biosynthesis, but was less potent than $0.5 \mu \mathrm{M}$ L-MTX; $2 \mu \mathrm{M}$ D-MTX was no different from control (not shown). Inhibition of dTMP biosynthesis by D-MTX was not studied previously [2]. D,L$e, t$-FMTX at $2 \mu \mathrm{M}$ took longer to initiate inhibition of dTMP biosynthesis than did $0.5 \mu \mathrm{M}$ L-MTX (Fig. 2B). D$e, t$-FMTX at $2.8 \mu \mathrm{M}$ was not different from control; $10 \mu \mathrm{M}$ D-e,t-FMTX eventually caused inhibition but took much longer than $2 \mu \mathrm{M} \mathrm{D}, \mathrm{L}-e, t$-FMTX. Thus, D-MTX and D-e,tFMTX were weaker inhibitors of dTMP biosynthesis than were the corresponding L-enantiomers.

Outgrowth inhibition. Using a 120-hr exposure period, L-MTX was about 2- and 33-fold more effective than D, LMTX and D-MTX, respectively, as an inhibitor of CCRFCEM cell growth (Table 1). These results are similar to earlier studies on L1210 cells using unpurified D-MTX, but dissimilar to earlier results with CCRF-CEM cells where the $\mathrm{EC}_{50}$ for purified $\mathrm{D}-\mathrm{MTX}$ was $>1000 \mathrm{nM}$ [2]. It is doubtful that trace contamination of our D-MTX by LMTX ( $\leqslant 2 \%$. above) accounts for the difference in potency found in the two studies. A likely source for the difference is the conditions used to assess growth inhibition. Earlier studies used initial densities of $5 \times 10^{4}$ cells $/ \mathrm{mL}$ and allowed 3 generations of growth [2], while our initial density was $1 \times 10^{4}$ cells $/ \mathrm{mL}$ and allowed 5-6 generations. Slower uptake of D-MTX and weaker inhibition of DHFR may mean that a longer exposure time is requircd for the effects to be evident (cf. Fig. 2). D-e,t-FMTX was also a much less potent inhibitor than $\mathrm{D}, \mathrm{L}-\varepsilon, t-\mathrm{FMTX}$ of CCRF-CEM cell growth (Table 1 ).

At $92-97 \%$ growth inhibition, effects of each compound could be reversed by the simultaneous presence of $10^{-7} \mathrm{M}$ leucovorin (not shown). In addition, in one experiment, CCRF-CEM sublines resistant to MTX because of reduced transport or increased DHFR were cross-resistant to DMTX and D-e,t-FMTX. These results indicate that each drug was acting as an antifolate. Similar protection and cross-resistance experiments were not reported previously with D-MTX [2].

Data presented here indicate that MTX analogs containing D-Glu or D-erythro,threo-4-fluoroGlu exert growth inhibitory effects by mechanisms similar to MTX, but are markedly less potent. Decreased potency of both D-species appears to be a result of decreased uptake and weaker DHFR inhibition. Inability of $D$-enantiomercontaining analogs to form polyglutamate derivatives [18] probably contributed little to decreased potency here since polyglutamylation is not essential under continuous exposure conditions [3]. Previously [2], only weaker DHFR inhibition was recognized as a factor in the decreased potency of D-MTX. The present results thus provide further evidence that D-MTX occurring [2] as a contaminant in MTX should not be of major concern in its clinical use. These results also validate the use of MTX analogs containing $\mathrm{D}, \mathrm{L}$-amino acids. Specifically, the results validate our earlier assumption that D-e,t-FMTX is essentially inactive compared to $L-e, t$-FMTX in the biological systems employed. Further, the results demonstrate that 4-fluorosubstitution in Glu does not alter stereospecificity in the folate-dependent systems examined. 
These results are also of significance in terms of the future use of $D, L-e, t$-FMTX in vivo. Plasma clearance of D-MTX is as rapid as that of L-MTX [2]; thus, if D,L-MTX was used, plasma ratios of D-MTX:L-MTX should not rise to a value where the $D$-isomer could interfere with the action of L-MTX. This observation and the similarity in properties of MTX and FMTX suggest that D-e,t-FMTX and $L-e, t$-FMTX should be cleared with similar kinetics. This, coupled with the low potency of the D-isomers, indicates that use of mixed isomers $\mathrm{D}, \mathrm{L}-e, t$-FMTX in vivo should not have significant therapeutic disadvantages.

In summary, analogs of MTX (4-amino-10-methylpteroylL-Glu) containing D-Glu (D-MTX) or D-erythro,threo-4fluoroGlu (D-e,t-FMTX) were characterized. D-MTX and D-e,t-FMTX were $>98$ and $>96 \%$ enantiomerically pure, respectively, by enzymatic assay. D-MTX and D-e,t-FMTX were less potent inhibitors of DHFR, $\left[{ }^{3} \mathrm{H}\right] \mathrm{MTX}$ uptake, and folate-mediated dTMP biosynthesis than the $L$ enantiomer-containing species. These properties were refiected in their decreased cytoxicity for CCRF-CEM cells compared to the L-enantiomer-containing species. These results indicate that MTX analogs containing D-enantiomers of Glu or Glu analogs are less active than the L-enantiomercontaining counterparts at each key step in the mechanism of MTX and these decreased activities combine to produce lower overall biological activity.

Acknowledgements-This research was supported in part by Grants CA43500 (J.J.M), CA24538 (J.J.M), and CA28097 (J.K.C.) from the National Cancer Institute, Department of Health and Human Services. R.F.S. receives support from the U.K. Cancer Research Campaign under Grant SP1391. D.M.F. was supported by Training Grant CA09072.

\section{* Grace Cancer Drug Center Roswell Park Memorial Institute \\ Buffalo, NY 14263 \\ U.S.A. \\ $¥$ Departments of Chemistry and Medicinal Chemistry \\ University of Michigan \\ Ann Arbor, MI 48109, \\ U.S.A. \\ $\$$ Division of Biotechnology \\ PHLS Centre for Applied \\ Microbiology and Research \\ Salisbury, Wilts SP4 OJG, \\ U.K.}

\section{REFERENCES}

1. Rosowsky A. Chemistry and biological activity of antifolates. Prog Med Chem 26: 1-252, 1989.

2. Cramer SM, Schornagel JH, Kalghatgi KK, Bertino $J R$ and Horvath $C$, Occurrence and significance of D-methotrexate as a contaminant of commercial methotrexate. Cancer Res 44: 1843-1846, 1984.

3. Galivan J, Inglese J, McGuire JJ, Nimec Z and Coward JK, $\gamma$-Fluoromethotrexate: synthesis and biological activity of a potent inhibitor of dihydrofolate reductase with greatly diminished ability to form poly- $\gamma$ -

† Corresponding author: John J. McGuire, Ph.D., Grace Cancer Drug Center, Roswell Park Memorial Institute, 666 Elm St., Buffalo, NY 14263. Tel. (716) 845-8249; FAX (716) 845-8857. glutamates. Proc Natl Acad Sci USA 82: 2598-2602, 1985.

4. McGuire, JJ, Graber M, Licato N, Vincenz C, Coward JK, Nimec Z and Galivan J, Biochemical and growth inhibitory effects of the erythro and threo isomers of $\gamma$-fluoromethotrexate, a methotrexate analogue defective in polyglutamylation. Cancer Res 49: 4517$4525,1989$.

5. McGuire JJ, Haile WH and Coward JK, Interaction of erythro- and threo- $\gamma$-fluoromethotrexate with human leukemia cell dihydrofolate reductase. Biochem Phar. macol 38: 4321-4325, 1989.

6. McGuire JJ, Russell CA, Bolanowska WE, Freitag CM, Jones CS and Kalman TI, Biochemical and growth inhibition studies of methotrexate and aminopterin analogues containing a tetrazole ring in place of the $\gamma$ carboxyl group. Cancer Res 50: 1726-1731 1990.

7. Abraham A, McGuire JJ, Galivan J, Kisliuk RL, Gaumont $Y$ and Nair MG, Folate analogues 34: Synthesis and antitumor activity of non-polyglutamylatable inhibitors of dihydrofolate reductase. $J$ Med Chem 34: 222-227, 1991.

8. McCullough JL, Chabner BA and Bertino JR, Purification and properties of carboxypeptidase $\mathrm{G}_{1}$. $J$ Biol Chem 246: 7207-7213, 1971.

9. McGuire JJ, Mini E, Hsieh P and Bertino JR, Role of methotrexate polyglutamates in methotrexate- and sequential methotrexate-5-fluorouracil-mediated cell kill. Cancer Res 45: 6395-6400, 1985.

10. Sherwood RF, Melton RG, Alwan SM and Hughes P, Purification and properties of carboxypeptidase $G_{2}$ from Pseudomonas sp. strain RS-216. Use of a novel triazine dye affinity method. Eur J Biochem 148: 447453,1985 .

11. Minton MP, Atkinson T and Sherwood RF, Molecular cloning of the Pseudomonas $\mathrm{CPG}_{2}$ gene and its expression in $E$. coli and Pseudomonas putida. $J$ Bacteriol 156: 1222-1227, 1983.

12. Foley GF, Lazurus H, Farber S, Uzman BG, Boone BA and McCarthy RE, Continuous culture of lymphoblasts from peripheral blood of a child with acute leukemia. Cancer 18: 522-529 1965.

13. Rosowsky A, Lazarus H, Yuan GC, Beltz WR, Mangini L, Abelson HT, Modest EJ and Frei E III, Effects of methotrexate esters and other lipophilic antifolates on methotrexate-resistant human leukemic lymphoblasts. Biochem Pharmacol 29: 648-652, 1980.

14. Mini E, Srimatkandada S, Medina WD, Moroson BA, Carman MD and Bertino JR, Molecular and karyological analysis of methotrexate-resistant and -sensitive human leukemic CCRF-CEM cells. Cancer Res 45: 317-325, 1985.

15. Licato NJ, Nimec Z, Galivan J, McGuire JJ and Coward JK, The synthesis of 4-deoxy-4-amino10-methylpteroyl-(4-fluoroglutamyl)- $\gamma$-glutamate, an unusual substrate for folylpoly- $\gamma$-glutamate synthetase and $\gamma$-glutamyl hydrolase. $J$ Med Chem 33: 1022-1027, 1990.

16. Bertino JR, Methotrexate: Molecular pharmacology. In: Cancer and Chemotherapy (Eds. Crooke ST and Prestayko AW), pp. 311-322. Academic Press, New York, 1981.

17. Chou T.C and Talalay P, Quantitative analysis of doseeffect relationships: The combined effects of multiple drugs or enzyme inhibitors. Ado Enzyme Regul 22: 27-55, 1984

18. McGuire JJ, Hsieh $P$, Coward $J K$ and Bertino JR, Enzymatic synthesis of folylpolyglutamates. Characterization of the reaction and its products. $J$ Biol Chem 255: 5776-5788, 1980 